\title{
Women Empowerment and Work-Life Balance of Women Engineers in the Malaysian Energy Sector: A Conceptual Framework
}

\author{
Nur Izzaty Shahirah Nor Sham ${ }^{1 *}$,Rohani Salleh ${ }^{2}$, and Sharifah Syahirah Syed Sheikh ${ }^{3}$ \\ Department of Management and Humanities, Universiti Teknologi PETRONAS \\ ${ }^{2}$ Department of Management and Humanities, Universiti Teknologi PETRONAS \\ Institute of Graduate Studies, Kolej Universiti Poly-Tech MARA
}

\begin{abstract}
Malaysian energy sector is listed as one of the sectors that have lower participation of women. This is due to the problem of attracting and retaining the women workforce within the field. The major reason women leave the energy sector especially in the engineering field, is due to the difficulties in balancing work-life. Women hold dual and triple roles where they are stucked between responsibilities as mother, wife, and daughter as well as responsibilities in the workplace. This situation contributes a great impact on their work-life balance. Empowering women in the sector could help in giving them more control in managing their work and family. Hence, this paper aims to provide an overview on women empowerment and its impact on work-life balance. In addition, this paper proposes a conceptual framework to analyze the level of women empowerment (welfare, access, conscientization, participation and control) and its impact on work-life balance of women engineers in Malaysian energy sector for future study. This paper will contribute to the knowledge on an area that is still relatively uncovered. Which refers to the impact of women empowerment and work-life balance of women engineers in energy sector. It is important for organizations to be aware about the importance of women empowerment and their employees work-life balance. Thus, organizations can take an appropriate intervention in order to empower their women talent and assist them to have better work- life balance.
\end{abstract}

\section{Introduction}

In Malaysia, almost half of the current total population are women (Department of Statistic, 2020). Democratization in education system and the changes in social norm has led to a more significant role of women in Malaysia. In fact, women have been claimed as a group which has contributed a huge impact on the advancement of the country. According to Anas Alam (2017), women play significant roles in the development of Malaysia and their participation in the workforce could potentially contribute additional income per capita of approximately US\$2,300 for the country. In addition, statistics from the World Bank (2019) indicated that women's participation in the Malaysian workforce has increased from $46.8 \%$ in 2010 to $55.2 \%$ in 2018 . This showed a positive trend towards the involvement of women in the Malaysian workforce in the various sectors.

Despite the increasing participation of women in the Malaysian workforce, the trend is rather different in the engineering field. Although the advancement of technology and the democratization of education especially in STEM (science, technology, engineering, and mathematics) has contributed to better participation of women in the male- dominated industry such as engineering, women are still underrepresented in the engineering and related fields (UNESCO, 2017). In Malaysia for example, female engineers are still under-represented as compared to male engineers. For example, according to the statistics from the Board of Engineers Malaysia, out of $26 \%$ of engineering female graduates, only $6 \%$ became professional engineers.

Several reasons have contributed to many women engineers left the profession. One of the reasons is due to the difficulties in balancing work and life matters. Long working hours, for instance, forced them to sacrifice time for their private lives (Maimunah \& Mariani, 2008). This situation led them to experience both personal and professional challenges that restricted them to retain in the engineering field (Izmayani, Khalijah, Husna \& Nurul Akmar, 2015). In 2017, Malaysia ranked number two in having the worst work-life balance after Japan (Hays, 2017). while, recently, Kuala Lumpur ranked $40^{\text {th }}$ out of 40 cities surveyed for the most holistic work-life balance (Wong, 2019). Women engineers, in particular, were claimed to be in a "sandwich generation", with high commitment in taking care of their children and the elderly (Norfarhanis, 2015). This situation contributes to low job satisfaction and motivation in performing their jobs. In certain scenarios, they felt confused about their priorities and oppressed by the choices available for them (Norfarhanis, 2015). Moreover, less autonomy over work, lack of participation in decision making and lack of achievement in work contribute to the decision of women to leave the engineering field (Ummu Sakinah, Ridzwan, Ramlee \& Zaliza, 2018; Izmayani et al, 2015). Women engineers were also seen as having lack of control over their job and were not allowed to perform challenging physical tasks, due to being seen as less capable and having limited skills. Employers and colleagues tend to question and doubt their ability and decision (Ummu Sakinah et al, 2018).

\footnotetext{
*Corresponding author: nur_18003358@utp.edu.my
} 
Energy sector plays an important role in the national economic development. For instance, the oil and gas industry is considered as one of the important contributors to energy sector and Malaysian economy. The energy sector through oil and gas itself contributed approximately $20 \%$ to the country's GDP in recent years (A Projection of Malaysian Energy Landscape, 2019). The energy sector is recorded as the sector that has a low participation of women engineers and has a gap in gender diversity. According to Liyana (2019) closing the gender gap and fostering gender diversity in the energy sector is crucial as women are key drivers for innovative and inclusive solutions in organizations.

Women empowerment become a global trend today in order to protect and uphold the right of women in terms of education, workforce and welfare. Moreover, women empowerment promotes gender equality which allows women to take an equal place in the economic and development process. In line with the 5th Sustainable Development Goals (SDGs) by the United Nations, gender equality and empowerment is fundamental for prosperous and sustainable world (United Nations, 2016). Empowering women engineers in the energy sector is seen as one of the initiatives that can give them greater control over their lives and careers. Being empowered means having full respect, freedom and a satisfying life. Thus, empowering women will assist them to achieve their full potential as engineers. According to Narayanan and Selvanathan (2017), women empowerment has a significant relationship with women work-life balance of working women. In fact, their decision to work and career success depends on their ability to balance their work - life.

The government initiatives also played an important role in upholding women's right in Malaysia. Various policies such as the National Policy on Women, 1989, Action Plan for the Advancement of Women, 1992, the establishment of Ministry of Women, Family and Community Development in 2001, the introduction of policy of having "At least $30 \%$ of Women in Decision-Making Position' in 2004 and declaring "2018 as the year of women empowerment" are some of the examples of initiatives taken by the Malaysian government in empowering women in this country. This paper aims to give an overview of women empowerment, specifically in relation to women engineers in Malaysia and how it impacted their work-life balance. In addition, this paper proposes a women empowerment framework to measure the level of women empowerment in the energy sector and its impact on work-life balance. A conceptual framework will be proposed for future study.

\section{Literature review}

\subsection{Work-Life Balance}

The term work-life balance originated way back in the 1970s due to two major events that triggered the initiation of work-life balance (Harrington, 2007). Firstly, it was due to the participation of women in the workforce in the 70s. The participation of women in the workforce urged organizations and companies to accommodate the facilities and the needs of working women especially involving childcare (Suhendro, 2018). Likewise, the second event was due to the introduction of the Employee Assistance Program (EAP), also in the 1970s, emphasized the wellness and work-life balance of employees. According to EAP, the productivity of an organization is affected when employees experience stress, illness, and depression (Harrington, 2007).

Work-life balance is defined as the ability of an employed individual to have a personal, social, and family life and enjoy it while concurrently addressing the need to fulfill their commitment upon work (Dykerhoff et al, 2012; Steene et al, 2010). Having a balance between personal life and work allows a person to have a meaningful and satisfying life. Work-life balance creates a situation where an individual is not extremely focused on work and at the same time, have sufficient space and time to spend quality time with family and attend to personal matters (Dykerhoff et al, 2012). One of the related concepts to work-life balance is the flexible working arrangement (FWA). FWA is related to the flexibility in conducting work by involving the development of skills and training to increase effectiveness and efficiency in works (Olmsted \& Smith, 1994). In other words, FWA is the alternative to traditional work arrangement such as "8-5" working hours. According to Subramaniam (2013;2011), FWA involves organization's practices that support employees' freedom to decide their working pattern and schedule.

The most common FWA initiative implemented in Malaysia is flexible working time, staggered working time, work-from-home, telecommuting, small-office-home-office (SOHO), and part-time work options (Subramanian, 2011). However, in Malaysia, there is a lack of legislation related to FWA. According to Nur Izzaty Shahirah, Rohani and Khalidah, (2020) FWA had become a global trend provided by employers that could drive an organization into the modern workforce. Still, this initiative has yet to be seen in Malaysia. Several efforts need to be undertaken by Malaysian companies to provide such benefits for women. Malaysian employees especially women, regardless of sector, need a supportive working environment to allow them to productively and effectively contribute to the organisation as well as their family. In the case of women engineers, being said that the common goal amongst women within the industry is to attain work-life balance (Hii, Kardini, Nurlili, Kiek \& Chan, 2014). According to Nurlidia Mansor, from UTP's Chemical Engineering Department, empowering women engineers could help them to have a greater work-life balance, also assisting them to use their full potential as engineers (Star2.com, 2019). The next paragraph will explain on the women empowerment concept in terms of offering women more control in handling their double and triple burden.

\subsection{Women Empowerment}

Women empowerment is widely used nowadays in protecting and supporting the rights of women all around the world. According to Parveen and Chaudhury (2009), women's empowerment can be defined as greater control of women over their own life and choices in terms of finance, knowledge, information, skills, political power and economic resources. According to Parveen and Chaudhury (2009), women's empowerment can be defined as greater control of women over their own life and choices in terms of finance, knowledge, information, skills, political power and economic resources. It also challenges the ideology of patriarchy in leadership and decision-making process which and strives for women's rights and equal opportunity between gender. Oxaal and Baden (1997) mentioned that women's empowerment does not 
in any way reduce the power of man. It just emphasized on more participation of women and man to work together to improve the equality of the gender in the country for country's development.

According to Kabeer (1994;1999) and Rowland (1997), women empowerment is the multi-dimensional nature of power which emphasized on the "power within" to transform the ability to control the resources and make decision. Besides, such power cannot be given directly but it needs to be self-generated by individuals or through an agency (Rowland,1997). The word empowerment originated from the idea of power which can be operated in four ways which are 'power to', 'power with', 'power within' and 'power over'. In this paper, women empowerment operationalized as 'power within' as stated by Kabeer $(1994,1999)$ and Rowland (1997). The 'power within' is self-generated and gives women greater control over their finance, knowledge, information, skills, political power and economic resources (Parveen $\&$ Chaudhury, 2009). It focuses on increasing awareness and desire for change among women themselves. The "power within' is the spiritual strength and the uniqueness of human beings, grounded by self-acceptance and self-respect to embrace differences and acknowledge gender equality and diversity in organizations (Rowland,1997). The next section will discuss the frameworks to measure women empowerment.

\subsection{Longwe's Women Empowerment Framework}

It is crucial to measure WE in order to gauge the extent it is practiced as well as to assist in the development of interventional measures and policies to support women at work. Many frameworks can be adopted and adapted to measure women empowerment such as Moser's Framework, Harvard Analytical Framework, Longwe's Women Empowerment Framework and Survey of Women Empowerment Index (SWPER). However, many of these frameworks have been developed to measure women empowerment in community contexts. This paper will next discuss Longwe's Empowerment Framework (WEF) to justify its relevance in measuring women empowerment at organizational level in Malaysia.

Longwe's Women Empowerment Framework (WEF) has been developed by Sara Hlupekile Longwe in 1995 (March, Smyth \&Mukhopadhyay, 1999). This framework's major objective is to help researchers in measuring the empowerment as well as to critically assess the intervention support for women empowerment (March et al, 1999). This framework is useful for planning, monitoring and evaluating the development of women -related programs and projects. The framework is useful as a guide in strengthening the commitment to empower women in terms of policies, plans and programmes.

In addition, WEF has been officially adopted by The United Nations (UN) and it emphasizes both on gender equality and women empowerment. According to Longwe, a high level of gender equality will contribute to the high level of empowerment. The WEF consists of five dimensions; also known as levels of equality arranged in hierarchical order [27], namely (i) welfare; (ii) access; (iii) conscientisation; (iv) participation; and (v) control as depicted in Figure 1.

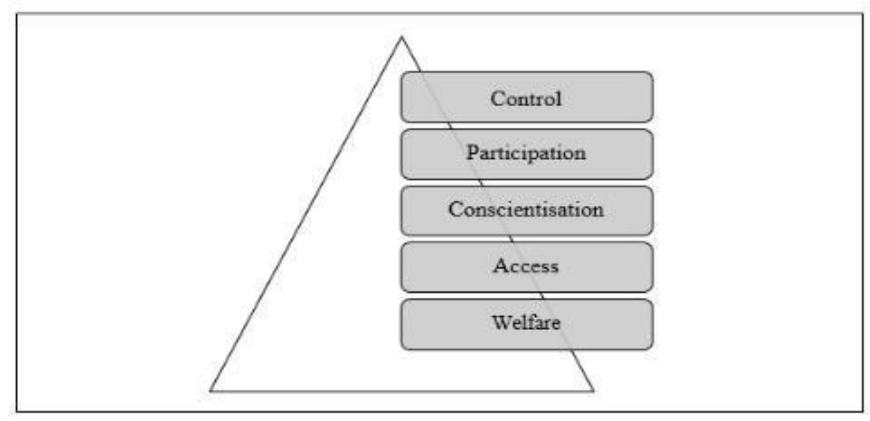

Figure.1: Longwe's Women Empowerment Framework (WEF)

To further explain Figure 1, the first level is Welfare. Welfare refers to the basic needs of women without attempting to solve the underlying structural causes that necessitate the provision of welfare services. It also refers to material welfare of women relative to man (March et al, 1999; Longwe, 2002; Sharifah Syahirah, Norehan \& Norfarhanis, 2016). In the context of working women, welfare means the assistance given by the employers at the workplace, including childcare facilities, maternity leave, protection from sexual harassment and flexible working hours (Norfarhanis, 2015; Amalia \& Rose, 2016). 
The next level is Access which refers to the equality towards education, training, resources, land and credit facilities. The lack of access on the resources stated above causes women to have barriers in achieving quality of life (March et al, 1999; Longwe, 2002; Sharifah Syahirah \& Norfarhanis, 2015; Sharifah Syahirah et al, 2016). The empowerment process occurs when women need to take the necessary actions to overcome the barrier of access to the above- mentioned facilities. According to Amalia and Rose (2016), women must experience equal access on the resources and benefits at the workplace; for example, training and career development opportunities, information and communications technology (ICT), equal treatment on job promotions and also opportunities for furthering studies.

The third level, Conscientisation refers to the actions undertaken by women to close the gender gap and reduce gender inequalities (March et al, 1999; Longwe, 2002; Sharifah Syahirah et al, 2016). According to Teberg (2011) andNorfarhanis (2015), Conscientisation involves an understanding on the differences between gender and the belief that gender relations should be fair and not based on the domination of one side.

The next level is Participation, which refers to the ability of women to take part in discussions and decision making in organizations, without barriers such as inequality in participation due to cultural interpretation ( Sharifah Syahirah et al, 2016). According to Longwe (2002), Teberg (2011) andSharifah Syahirah and Norfarhanis (2015), it is important for women to get mobilized in order to reach the desired level of participation in organizations. Women will be empowered to increase their representativeness by organizing themselves and working collectively.

Lastly, the highest level is Control. According to March, Smyth and Mukhopadhyay (1999) this level reflects women's control in decision making, whereby both women and men equally share power and control, leading to no domination and/or discrimination. At this level, women will have full control and freedom to make decisions in relation to their own lives, their children's lives and play active roles in the development of the nation (Sharifah Syahirah et al, 2016). In the workplace, they are able to express their opinions, control their workload and are free to conduct their work with minimal constraints (Noor Rahamah, 2012).

\section{The Impact of Women Empowerment on Work-Life Balance}

\subsection{Women empowerment and work-life balance}

Empowerment enhances women's ability to decide and choose what is best for them to reduce their double burden (Sharifah Syahirah, 2010). The equal opportunity and equal participation of women in relative with men increases the ability of women to have greater work-life balance (Norfarhanis, 2015). This is because women have control in managing their work and personal life since their voice and demand being counted by the employer. As mentioned in Andreasssi and Thompson (2008), equal opportunity urges the organization to improve the status of women employees through the implementation of organizational support for work-life balance. According to Akdağ (2012) empowerment is one of the key factors of work-life balance. The sense of gaining control positively affect mental, emotional and physical of individual, thus, directly results in the balance between work and personal life (Akdağ, 2012).

\subsubsection{Welfare and work-life balance}

Childcare facilities, maternity leave, freedom from sexual harassment and flexible working hours among important welfare assistance needed by working women. The flexible working arrangement is important to ensure the welfare of working women. It helps working women to be more productive and motivated in conducting their work as they can manage their time flexibly (Chung \& Lippe, 2018). Recently, the Malaysian government had decided to revise the maternity leave for all female worker in the private sector from 60 days to 90 days. To balance work and personal life, flexibility is considered one of the keys. A study conducted by Deery and Jago (2009) mentioned that flexible work practices, such as, flexible working schedules, working from home, flexible working options, access to unpaid and paid leave and job sharing are a few initiatives that could create work-life balance (Kimpah \& Raudeliūnienė, 2014).

\subsubsection{Access and work-life balance}

The lack of access to welfare resources caused women to acknowledge their barriers in achieving the quality of life. According to Amalia and Rose (2016), women must experience equal access to the resources and benefits at the workplace; for example, training and career development opportunities, information and communications technology (ICT), equal treatment on job promotions and opportunities for furthering studies. In addition, such access allows women to improve their skills, make the work easier, reduce their work stress and achieving greater work-life balance (Sharifah Syahirah et al, 2016). 


\subsubsection{Conscientisation and work-life balance}

It is crucial to create mutual understanding among gender and make them believe that treatment between women and men should be fair. According to Sharifah Syahirah et al (2016) when women are more conscious, they will be able to recognize that gender bias occurred due to unequal treatment in the workplace. It leads to the awareness that women also have a right to make a decision and compete with men in a good way to create mutual understanding (March et al, 1999; Sharifah Syahirah et al, 2016). According to Kimpah and Raudeliūnienè (2014) no gender inequality or discrimination at the workplace will create satisfaction at work, hence, conscientisation on that matter will increase women's quality of life and work-life balance.

\subsubsection{Participation and work-life balance}

Participation increases women's representation by allowing them to manage themselves by working collectively (Longwe, 2002). When women are not being neglected and their opinions are being counted in decision making, it shows that women's position is being recognized. Gaining consensus with colleagues in making a decision is important in avoiding conflict in the workplace. Having good cooperation and understanding with the top management and colleagues is also considered as one of the good indicators that shows women can participate in meetings and discussions (Narayanan \& Selvanathan, 2017). Thus, it creates a good working environment as well as enhances women's work-life balance (Amalia \& Rose, 2016).

\subsubsection{Control and work-life balance}

The control level shows the women's direct control over the access to resources at par with men (Longwe, 2002). Control level shows that there is a balance of power between gender, without domination and discrimination (Longwe, 2002; Sharifah Syahirah et al, 2016). Having control at the workplace allows women to decide and consider the best decision for their career whilst prioritizing their family and personal matters. According to Sharifah Syahirah and Norfarhanis (2015), at the control level, women have the power to control their work jurisdiction without any barriers. Work-life balance can be achieved when women have autonomy, centrality, and control over their job and personal life. Aligned with Akdağ (2002) work-life imbalance caused by a lack of autonomy and centrality in work leads to the disturbance on employees' performances. Reaching the control level means completing the process of empowerment (Longwe, 2002).

\section{Proposed Research Framework for Future Research}

Based on the previous studies and review of literature, the following framework is proposed to be investigated in future research. The framework is grounded by the empowerment theory by Zimmerman (2000). Empowerment theory gives ways to analyze the construct in different contexts and to study the empowerment process. For example, this theory allows the researcher to study the different contexts of empowerment in terms of personal, organizational and community. Empowerment allows individuals and organizations to see a closer relationship between their goals and how to achieve it (Mechanic, 1991). It shows the relationship between effort and the life outcome that affect an individual's life. Applying this theory in the organization may involve organizational processes and structure which will enhance the access and participation of employees and improve organizational effectiveness for goal achievement. In applying with this study, this theory portrays the empowerment of women in terms of welfare, access, conscientisation, participation, and control and it impacts on women engineers' work-life balance. Work-life balance is considered as a result that affects an individual's life. In fact, it will also influence the decision of women engineers whether to remain or to leave the sector. 


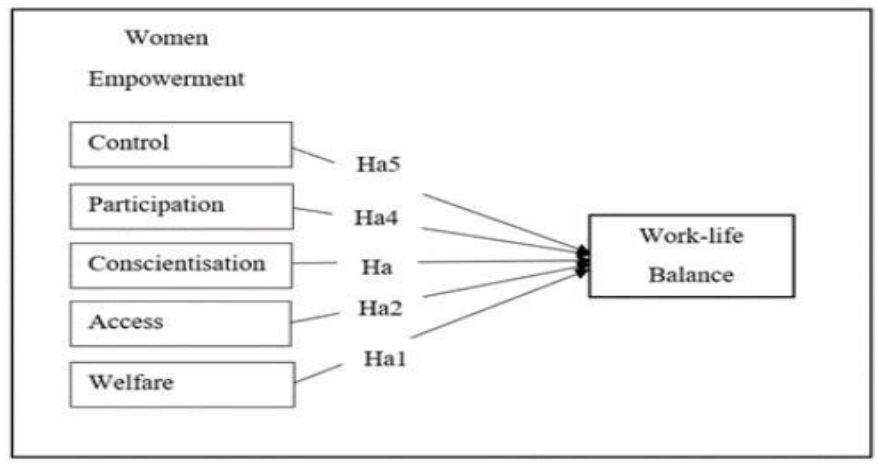

Fig.2. Conceptual Framework

\section{Conclusion}

Work-life balance is a very important element for working women, especially in engineering. The unpredictable nature of engineering arenas become a challenge for women in this industry to balance out their dual and triple roles. Many women engineers leave the field due to the challenges of balancing work-life. This paper proposes a conceptual framework for future study on the impact of women empowerment and the work-life balance of women engineers in energy sector. The empowerment of women will affect the work-life balance of women in the sector and contribute to the future participation of women engineers in energy sector. This effort will help the energy sector to close the gender gap and increase the percentage of women engineers within the sector. Besides, it will help organizations to promote greater gender equality and empower women engineers by uplifting their potential, whilst ensuring better work -life balance and give greater life satisfaction. Empowering women in the energy sector, supporting gender balance and creating gender diversity are important in fostering the Malaysian energy sector. Achieving gender diversity will close the gender gap, and give benefits for industry, organization, and country.

\section{References}

A Projection of Malaysian Energy Landscape. (2019). Energy Malaysia. Retrieved from https://www.st.gov.my/contents/files/download/112/Energy_Malaysia_18_(Online).pdf

Akdağ, F. (2012). Impact of Empowerment on Work-life Balance of Employees Well-being Cambridge Business \& Economics Conference. Cambridge, UK

Amalia Madihie \& Rose Amira Siman. (2016). "Issues Occurrence of Career Success Among Female Engineers. "Journal of Cognitive Sciences and Human Development Vol. 2 (1): 24-36.

Anas Alam. (2017, January 11). Women: The key to a brighter Malaysia. Astro Awani. Retrieved from Astro Awani Online:http://english.astroawani.com/malaysia-news/women-key-brighter-malaysia-12868

Andreassi, J. K. \& Thompson, C. A. (2008). "Work-Family Culture: Current Research and Future Directions." from https://www.researchgate.net/publication/27

Andreassi J., \& Thompson C. (2004), Work-Family Culture. Basic Concepts \& Definitions, School of Business, Baruch College, CUNY

Department of Statistic Malaysia. (2020). Current Population Estimates, Malaysia, 2018-2019. Retrieved from https://www.dosm.gov.my/v1/index.php?r=column/cthemeByCat\&cat=155\&bul id=aWJZRkJ4UEdKcUZpT2tVT090S npydz09\&menu

Dyckerhoff, C. S.-., et al. (2012). Women Matter: An Asian Perspective Harnessing Female Talent to Raise Corporate Performance. Australia, McKinsey \& Company

Fouad, A. N., Singh, R., Fitzpatrick, E. M., \& Liu, J. P. (2012). Stemming The Tide: Why Women Leave Engineering. Women in Engineering 2012 Report. 
Hays (2017). "Japan least performs in Asia when it comes to work-life balance ". 2019, from Japan least performs in Asia when it comes to work-life balance

Hii, R., Kardani, I.,Nurlili Elillza., N. Kiek, J. N., \& Chan, W. C. (2014). Empowering Women in the Oil and Gas Industry. International Petroleum Technology Conference. doi:10.2523/IPTC-17998-MS

Izmayani Saadin, Khalijah Ramli, Husna Johari \& Nurul Akmar Harin. (2015). Women and Barriers for Upward Career Advancement - A Survey at Perak State Secretariat, Ipoh, Perak. Procedia Economics and Finance 35: 574-581.

Kabeer, N. (1994) Reversed Realities: Gender Hierarchies in Development Thought, London: Verso Publication.

Kabeer, N. (1999). Resources, agency, achievement: Reflections on the measurement of women's empowerment. Development and Change. 30(3). pp. 435-464. $\quad$ Retrieved from https://www.utsc.utoronto.ca/ kmacd/IDSC10/Readings/research\%20design/empowerment.pdf (accessed in November 2019)

Longwe, S. H. (2002). Addressing Rural Gender Issues: A Framework for Leadership and Mobilization. Paper presented at the III World Congress for Rural Women, Madrid.

March, C., Smyth, I. A., \& Mukhopadhyay, M. (1999). A guide to gender-analysis frameworks. Oxford: Oxfam

Maimunah Ismail \& Mariani Ibrahim (2008). "Barriers to career progression faced by women: Evidence from a Malaysian multinational oil company." Gender in Management: An International Journal 23: 51-66.

Norfarhanis Mohd Shukri. (2015). The Implementation of "At Least 30\% of Women In Decision Making Policy" In Malaysia Public Sector: Women Empowerment and Quality of Life Analysis. Master Dissertation, Universiti Teknologi MARA.

Noor Rahamah Hj. Abu Bakar. (2012). Malaysian women in management. GEOGRAFIA OnlineTM Malaysia Journal of Society and Space, 8(4), 12-20. Retrieved from http:/www.ukm.my/geografia/images/upload/2a.geografia-jul 2012rahamah-ukm-english-edited 30.7.12.pdf

Nur Izzaty Shahirah Nor Sham, Rohani Salleh., \& Khalidah Khalid Ali. (2020). Reimagining Women Empowerment from an Organizational Perspective: A Malaysian Experience. Malaysia Labour Review, 14(1), 59-67.

Oxaal, Z., \& Baden, S. (1997). Gender and empowerment: definitions, approaches and implications for policy. Brighton, UK: University of Sussex.

Parveen, S \& Chaudhury, M. R. (2009). Micro-Credit Intervention and Its Effects on Empowerment of Rural Women: The BRAC Experience. Bangladesh Research Publications Journal, 2(3): 641- 647.

Rowlands, J. (1997). Questioning empowerment: working with women in Honduras. Oxfam: Dublin

Sharifah Syahirah Syed Sheikh. (2010). Pemerkasaan representasi politik wanita di Malaysia: analisis pilihan raya umum ke-12 (PRU12) 2008. The Journal of Administrative Science. 7(1). 11-37.

Sharifah Syahirah, \& Norfarhanis. (2015). Affirmative Policy Implementation and Women Empowerment In Malaysian Public Sector. Australasian Conference on Business and Social Sciences, (pp. 367-374). Sydney.

Sharifah Syahirah, Norfarhanis \& Norehan Hussain. (2016). A gender quota policy implementation and women empowerment in the Malaysian public sector sector. Australian Journal of Sustainable Business and Society. 59-68.

Star2.com (2019). "Engineering gender diversity: Take a step towards success at UTP". 2019, from https://www.star2.com/living/2019/02/07/utp-engineering-gender diversity/\#Kyq7X5dIwbVUerD2.99.

Steene, M. V., et al. (2010) Work life work life Keeping the Work-life balance. Women on the Frontline Vol. 6, 24-25

TalentCorp. (2018). Hannah Yeo: Work-life practices a must to ready Malaysia for future of work. Retrieved from https://www.talentcorp.com.my/resources/press-releases/hannah-yeoh-work-life-practices-a-must-to-ready-malaysiafor-future-of-work 
The Star Online. (2019). Yeo: Malaysia gains with greater women participation in workforce. Retrieved from The Star Online:https://www.thestar.com.my/news/nation/2019/03//

Thompson, C. A., Beauvais, L. L., \& Lyness, K. S. (1999). When work-family benefits are not enough: The influence of work-family culture on benefit utilization, organizational attachment, and work-family conflict. Journal of Vocational Behavior, 54, 392-41

Trübswetter, A., Hochfeld, K., \& Schraudner, M. (2016). Corporate Culture Matters - What Kinds of Workplaces Appeal to Highly Skilled Engineers? International Journal of Gender, Science and Technology, 8(1), 46-66

Ummu Sakinah Subri, Ridzwan Che' Rus, Ramlee Mustapha and Zaliza Hanapi. (2018). "A Review of Job Challenges Factors for Women Engineer." International Journal of Academic Research in Business and Social Sciences Vol. 8(No. $3)$.

United Nation: Gender Equality and Women Empowerment. (2016). https://www.un.org.com

UNESCO. (2017). Women still a minority in engineering and computer science: United Nations Educational, Scientific and Cultural Organization. Retrieved 2019, from http://www.unesco.org/new/en/media-services/singleview/news/women_still_a_minority_in_engineering_and_computer_science/

Vaughan, A. (2017). Energy sector faces struggle to find the female engineers of the future. from https://www.theguardian.com/business/2017/jan/28/drax-power-station-energy-companies-women.

Warren, J. A., \& Johnson, P. J. (1995). The impact of workplace support on workfamily role strain. Family Relations, 44, 163-169

Wong, L. Z. (2019, August 7). KL lowest among 40 cities in terms of work-life balance. TheStar. Retrieved from https://www.thestar.com.my/lifestyle/living/2019/08/07/kl-ranks-lowest-among-40-cities-in-terms-of-work-life-balance

World Bank. (2019). Breaking Barrier: Toward better opportunities for women in Malaysia. Retrieved from https:/www.worldbank.org/en/country/malaysia/publication/breaking-barriers-toward-better-economic-opportunities- forwomen-in-malaysia 